\title{
Interactions between Streptococcus suis serotype 2 and different epithelial cell lines
}

\author{
Mélanie Lalonde, Mariela Segura, Sonia Lacouture \\ and Marcelo Gottschalk
}

Groupe de Recherche sur les Maladies Infectieuses du Porc, Faculté de médecine vétérinaire Université de Montréal, CP 5000, Saint-Hyacinthe, Québec, Canada J2S 7C6
Author for correspondence: Marcelo Gottschalk. Tel: +1 4507738521 ext. 8374. Fax: +1 4507788108 . e-mail: gottschm@medvet.umontreal.ca

Streptococcus suis is an important swine pathogen responsible for cases of sudden death, septicaemia, meningitis, endocarditis and pneumonia. It is also recognized as a zoonotic agent in people occupationally exposed to pigs or pig products. Knowledge on virulence factors of S. suis serotype 2 is limited and the pathogenesis of the infection is poorly understood. It has been suggested that the disease due to $S$. suis serotype 2 begins with colonization of the nasopharyngeal epithelium, followed by either spread within the respiratory tract or invasion of the bloodstream. The mechanisms involved in the access of bacteria from the bloodstream to the central nervous system are unknown. It is possible that epithelial cells of the choroid plexus also play an important role in the pathogenesis of the meningitis. Different interactions (adhesion, invasion and toxic effects) of $S$. suis serotype 2 with epithelial cell lines [LLCPK1, PK(15), A549, HeLa and MDCK] were studied and compared to those of a human pathogen which also causes meningitis, group B Streptococcus (GBS). The results showed that $S$. suis serotype 2 , in contrast to GBS, is able to adhere to but not to invade epithelial cells. The adhesin(s) involved seem(s) to be partially masked by the capsule and are a part of the cell wall. The haemolysin produced by $S$. suis serotype 2 is responsible for a toxic effect observed on epithelial cells. The results described give additional evidence that pathogenesis of the infection differs between S. suis and GBS. In particular, it is possible that suilysin-positive $S$. suis strains use adherence and cell injury, as opposed to direct cellular invasion, as part of a complicated multistep process which leads to bacteraemia and meningitis in pigs.

Keywords: Streptococcus suis, epithelial cells, adhesion, cytotoxicity, haemolysin (suilysin)

\section{INTRODUCTION}

Streptococcus suis is an important swine pathogen responsible for cases of sudden death, septicaemia, meningitis, endocarditis and pneumonia (Higgins \& Gottschalk, 1999). Of the 35 serotypes of S. suis, serotype 2 is the most prevalent in diseased animals (Higgins \& Gottschalk, 1999). This serotype is also recognized as a zoonotic agent since it has been identified as a cause of septicaemia, endocarditis and meningitis in

Abbreviations: BBB, blood-brain barrier; CNS, central nervous system; CPS, polysaccharidic capsule; $\mathrm{GbO}_{3}$, trihexosylceramide; GBS, group $\mathrm{B}$ Streptococcus; LDH, lactate dehydrogenase; MEM, Minimal Essential Medium; SEM, scanning electron microscopy; TEM, transmission electron microscopy; THB, Todd-Hewitt broth. humans, particularly those occupationally exposed to pigs or pig products (Trottier et al., 1991; Arends \& Zanen, 1988).

Knowledge on virulence factors of $S$. suis serotype 2 is limited. Several virulence factor candidates have been proposed, such as the polysaccharidic capsule (CPS), which confers resistance to phagocytosis (Charland et al., 1998; Smith et al., 1999), virulence-related proteins (Vecht et al., 1991) and a haemolysin (named suilysin) belonging to the family of antigenically related cholesterol-binding cytolytic toxins (Gottschalk et al., 1995; Jacobs et al., 1994). Despite the fact that the CPS is an important virulence factor, non-virulent strains are also well encapsulated. Unlike European strains, most virulent North American strains do not produce all 
virulence-related proteins (Chatellier et al., 1999; Gottschalk et al., 1998; Segers et al., 1998). An adhesin, named $\mathrm{P}$ adhesin, has also been described. This adhesin recognizes the disaccharide galactosyl- $\alpha 1-4$-galactose present in the glycolipid trihexosylceramide $\left(\mathrm{GbO}_{3}\right)$ that belongs to the P blood group antigen system (Haataja et al., 1993). However, its role as a virulence factor has not yet been confirmed.

The pathogenesis of the meningitis caused by S. suis serotype 2 is also unclear and is possibly the result of a multistep process. It is believed that disease due to this micro-organism begins with the colonization of the nasopharyngeal tissue, followed by spread within the respiratory tract and invasion of the bloodstream. Mechanisms used by $S$. suis type 2 to gain access to the bloodstream are not known. It is possible that $S$. suis interacts with respiratory epithelial cells to enter into the bloodstream to cause overwhelming sepsis. Although the presence of the capsule would prevent phagocytosis (Charland et al., 1998; Smith et al., 1999), the mechanisms which enable $S$. suis to disseminate in the body and more particularly in the central nervous system (CNS) are not well understood. At one point, free bacteria would have to pass by or through the cells which form the blood-brain barrier (BBB). The BBB, which is formed by the arachnoid membrane, the brain microvascular endothelial cells and the choroid plexus, maintains the homeostasis within the CNS. It has already been suggested that bacteria may enter the CNS through the choroid plexus, which has an exceptionally high rate of blood flow that may imply a higher bacterial influx (per unit of time) to this site than to other anatomic locations in the CNS (Tunkel \& Scheld, 1993). The principal characteristic of the epithelial cells of the choroid plexus is the presence of tight junctions that regulate fluid, macromolecule and cell trafficking on both sides of the layer (Betz \& Goldstein, 1986; Tuomanen, 1996).

In order to obtain additional information on the pathogenesis of the infection caused by $S$. suis type 2, different interactions between this micro-organism and epithelial cells were studied. More specifically, the objective of this study was to evaluate the ability of $S$. suis serotype 2 to adhere to, invade and damage different epithelial cell lines.

\section{METHODS}

Bacterial strains and growth conditions. The European suilysin-positive virulent strains S735 (reference strain ATCC 43765 ) and 31533 (kindly supplied by Dr M. Kobisch, AFSSA Ploufragan, France) as well as the North American suilysinnegative virulent strain AAH4 (kindly provided by Dr Brad Fenwick, Kansas State University, USA) were used. The isogenic unencapsulated mutant $2 \mathrm{~A}$, derived from strain S735 by Tn916 transposition, was also studied (Charland et al., 1998). The group B Streptococcus (GBS) type III strain COH1 (kindly provided by Dr C. Rubens, Children's Hospital and Medical Center, Seattle, WA, USA), was used as a positive control. Bacteria were grown on blood agar plates and isolated colonies were used as inocula in Todd-Hewitt broth (THB;
Difco) for growth to mid-exponential phase $\left(\mathrm{OD}_{600}\right.$ of $0 \cdot 4$, equivalent to $\sim 10^{8}$ c.f.u. $\mathrm{ml}^{-1}$ ). An accurate determination of the c.f.u. $\mathrm{ml}^{-1}$ in the final suspension was carried out by plating on THB agar.

Cell cultures. Several epithelial cell lines were used, all obtained from the American Type Culture Collection (ATCC). The A549 (LLC-185) line was derived from a human lung carcinoma. The HeLa (CCL-2) line was derived from a human cervix carcinoma. The MDCK (CCL-34.1) cell line was derived from the kidney of a normal adult dog and forms polar monolayers. The PK(15) (CCL-33) derived from the original PK-2a, that was initiated from the kidney of an adult pig. Finally, the LLC-PK1 (CL-101) line was derived from the kidney of a normal juvenile pig. The A549 cell line was propagated in F-12K medium (Gibco) whereas all other cell lines were propagated in Minimal Essential Medium (MEM; Gibco). The different media were supplemented with $10 \%$ heat-inactivated fetal bovine serum (Gibco), L-glutamine and penicillin-streptomycin (Gibco), as recommended by the ATCC. Cells were incubated at $37^{\circ} \mathrm{C}, 5 \% \mathrm{CO}_{2}$ in a humid atmosphere, at a 1:8 dilution passage and grown for 2-3 d. The cell lines were used before passage 35 for all experiments. For adherence, invasion and cytotoxicity assays, cells were transferred after trypsination to 24-well tissue culture plates (Falcon) and incubated to confluence ( $\sim 10^{5}$ cells per well). Before the experiment, cells were washed twice in HBSS buffer (Gibco). Then, $0.4 \mathrm{ml}$ of medium without antibiotics was added.

Epithelial cell invasion assay. The assay was performed as described by Rubens et al. (1992) with some modifications. Briefly, exponential-phase bacteria were pelleted, washed once with PBS (140 mM NaCl, $3 \mathrm{mM} \mathrm{KCl,} 10 \mathrm{mM} \mathrm{NaH}{ }_{2} \mathrm{PO}_{4}$ $1.5 \mathrm{mM} \mathrm{KH}_{2} \mathrm{PO}_{4}, \mathrm{pH} \mathrm{7.3)}$ and resuspended in fresh cell culture medium without antibiotics. Bacterial suspensions diluted in cell culture medium $\left(0 \cdot 1 \mathrm{ml}\right.$, inocula between $10^{2}$ and $\left.10^{7}\right)$ were added to wells containing a monolayer $\left(\sim 10^{5}\right.$ cells $)$ of epithelial cells in $0.4 \mathrm{ml}$ medium (m.o.i. of 100 to 0.001 bacteria per cell). The plates were centrifuged at $800 \mathrm{~g}$ for $10 \mathrm{~min}$ to bring bacteria to the surface of the monolayer. The plates were incubated for $2 \mathrm{~h}$ at $37^{\circ} \mathrm{C}$ with $5 \% \mathrm{CO}_{2}$, to allow cellular invasion by the bacteria. The monolayers were then washed three times with PBS, $1 \mathrm{ml}$ of cell culture medium containing $100 \mu \mathrm{g}$ gentamicin and $5 \mu \mathrm{g}$ penicillin $\mathrm{G} \mathrm{ml}^{-1}$ was added to each well, and the plates were incubated for $2 \mathrm{~h}$ at $37{ }^{\circ} \mathrm{C}, 5 \% \quad \mathrm{CO}_{2}$ to kill extracellular and surface-adherent bacteria. The monolayers were washed three times with PBS, and cells were disrupted by the addition of $0.5 \mathrm{ml}$ sterile deionized water and repeated pipetting to liberate intracellular bacteria. One hundred microlitres from each well was plated onto THB agar and incubated overnight at $37^{\circ} \mathrm{C}$. The rate of invasion was expressed as the total number of c.f.u. recovered per well. Assays were performed in duplicate and repeated at least three times.

Epithelial cell adherence assays. Total cell-associated (invading plus surface-adherent) bacteria were quantified as for the cellular invasion assay but without antibiotic treatment. After different incubation times (see Results), cells were washed five times with PBS, lysed as described above and quantified by quantitative plating. Bacterial adherence was determined by subtracting invading bacteria from total cellassociated bacteria. All assays were performed in duplicate and repeated at least three times. In experiments testing inhibition of adherence, epithelial cells were pre-incubated with $100 \mu \mathrm{g}$ purified $S$. suis cell wall ml ${ }^{-1}$ for $60 \mathrm{~min}$ at $37^{\circ} \mathrm{C}$ or bacteria were pre-incubated with $1 \mu \mathrm{g}$ Gal $\alpha 1-4 \mathrm{Gal} \beta 1-$ 
4Glc $\beta$-O-CETE-BSA ml ${ }^{-1}$ (Cedarlane) (Haataja et al., 1993) for $10 \mathrm{~min}$ at $4{ }^{\circ} \mathrm{C}$ before the test. Implication of proteins as adhesins was studied by treating bacteria for $1 \mathrm{~h}$ at $37^{\circ} \mathrm{C}$ with $1 \mathrm{mg}$ trypsin $\mathrm{ml}^{-1}$ (Sigma) or $1 \mathrm{mg}$ proteinase $\mathrm{K} \mathrm{ml}^{-1}$ (Boehringer Mannheim).

Purification of S. suis cell wall. S. suis cell wall was purified as previously described (Segura et al., 1999). Briefly, the unencapsulated strain $2 \mathrm{~A}$ was grown in 1 litre of THB for $12 \mathrm{~h}$ at $37^{\circ} \mathrm{C}$ with agitation to a cell concentration of $\sim 2 \times 10^{8}$ c.f.u. $\mathrm{ml}^{-1}$. Bacteria were harvested by centrifugation $\left(12000 \mathrm{~g}, 15 \mathrm{~min}, 4^{\circ} \mathrm{C}\right)$, washed and resuspended in $2 \%$ $(\mathrm{w} / \mathrm{v})$ boiling SDS. The denatured cells were then disintegrated by ultrasound treatment (Sonics \& Materials-Danbury) for $5 \times 8 \mathrm{~min}$. The suspension was centrifuged $(3000 \mathrm{~g}, 30 \mathrm{~min})$ to remove unbroken cells, and the supernatant was centrifuged at $30000 \mathrm{~g}$ for $30 \mathrm{~min}$ at room temperature to sediment out the cell wall material. The pellet was resuspended in distilled water and subjected to a second ultrasound cycle $(5 \times 8 \mathrm{~min})$ to assure complete cell disruption. This crude cell wall material was washed six times by centrifugation $(30000 \mathrm{~g}$, $30 \mathrm{~min}$, room temperature) in distilled water and subsequently treated at $37^{\circ} \mathrm{C}$ with $50 \mu \mathrm{g}$ pancreatic DNase $\mathrm{I} \mathrm{ml}^{-1}$ plus $100 \mu \mathrm{g} \mathrm{RNase} \mathrm{ml}^{-1}$ (Sigma) for $2 \mathrm{~h}$, followed by $100 \mu \mathrm{g}$ trypsin $\mathrm{ml}^{-1}$ (Gibco) for $12 \mathrm{~h}$. Cell wall was sedimented by centrifugation and resuspended in $2 \%(\mathrm{w} / \mathrm{v}) \mathrm{SDS}$ at $100{ }^{\circ} \mathrm{C}$ in a water bath for $30 \mathrm{~min}$. Detergent was removed by 10 cycles of washing and the purified cell wall was lyophilized, weighed and stored in the dry state at room temperature.

Epithelial cell cytotoxicity assay. To determine cell cytotoxicity of S. suis, the lactate dehydrogenase (LDH) microtitre plate assay was performed as described by Nizet et al. (1997), with some modifications. Briefly, $10^{8}$ c.f.u. of exponentialphase bacteria were centrifuged, washed in PBS and concentrated in $1 \mathrm{ml}$ MEM without serum. Twofold serial dilutions in MEM were carried out and $100 \mu$ l of the different bacterial dilutions were added to wells of a 24 -well tissue culture plate containing a LLC-PK1 monolayer. Non-infected cells and bacteria in MEM without a LLC-PK1 monolayer were used as negative controls, whereas cells lysed with $500 \mu \mathrm{l}$ of sterile deionized water were used as a positive control. Plates were incubated at $37^{\circ} \mathrm{C}, 5 \% \mathrm{CO}_{2}$ for $4 \mathrm{~h}$ in most experiments (unless otherwise specified). At the end of the incubation period, a $75 \mu \mathrm{l}$ aliquot of each supernatant was transferred to a 96-well plate which was centrifuged at $3000 \mathrm{~g}$ for $30 \mathrm{~min}$ to pellet bacteria. LDH measurement was performed on $50 \mu \mathrm{l}$ aliquots of each centrifuged supernatant using a miniaturized version of the LDH colorimetric assay (Sigma) (Nizet et al., 1996). The percentage cytotoxicity was calculated as $\left[\left(A_{\text {bacteria }}-A_{0 \%}\right) /\left(A_{100 \%}-A_{0 \%}\right)\right] \times 100$, where $A_{0 \%}$ represents $A_{414}$ (UVmax; Molecular Devices) for non-infected cells and $A_{100 \%}$ represents $A_{414}$ for lysed cells. To determine if cytolytic components were secreted extracellularly, growth supernatants of late-exponential-phase bacteria were recovered by centrifugation at $3000 \mathrm{~g}$ for $10 \mathrm{~min}$, filtered on $0 \cdot 22 \mu \mathrm{m}$ filters and then added to LLC-PK1 monolayers as described above. The assay was also performed with purified suilysin at a concentration of $10 \mu \mathrm{g} \mathrm{ml}^{-1}$ (Charland et al., 2000). All the assays were performed in duplicate and repeated at least three times.

Inhibition of cytolytic activity. Heat-killed bacteria were used to verify if live bacteria were needed to obtain cytotoxicity. Exponential-phase bacteria $\left(10^{9}\right.$ c.f.u. $\left.\mathrm{ml}^{-1}\right)$ were killed by incubation in a $60^{\circ} \mathrm{C}$ waterbath for $45 \mathrm{~min}$ (Segura et al., 1999) and then added to LLC-PK1 monolayers for LDH measurement as described above. Inhibition of suilysin-related cytotoxicity was performed by incubating exponential-phase bacteria or purified suilysin $\left(10 \mu \mathrm{g} \mathrm{ml}^{-1}\right)$ in $400 \mu \mathrm{g}$ ethanolsoluble cholesterol ml $\mathrm{m}^{-1}$ (Sigma) for $1 \mathrm{~h}$ at $37^{\circ}$ before adding them to LLC-PK1 monolayers (Charland et al., 2000). Noninfected cells with cholesterol in culture medium were used as a negative control. Inhibition assays were always compared in parallel with non-treated bacteria or suilysin.

Suilysin purification. Suilysin was purified from supernatants of $16 \mathrm{~h}$ cultures of the highly haemolytic strain 31533. Supernatants were subjected to SDS-PAGE. A $52 \mathrm{kDa}$ band representing the suilysin (Gottschalk et al., 1995) was cut out, emulsified with Freund's complete adjuvant and injected intramuscularly to a New Zealand rabbit. The injection was repeated twice with Freund's incomplete adjuvant. The rabbit was bled 2 weeks after the last inoculation and the $\operatorname{IgG}$ were purified with a protein-A affinity column. The activity and specificity of the anti-haemoysin IgG were confirmed by inhibition of the haemolytic activity and immunoblotting with supernatant of a haemolysin-positive strain (results not shown). An affinity column was constructed with the monospecific antibodies using the Pierce CarboLink Coupling Gel (Pierce) and the haemolysin purified from culture supernatant of strain 31533 grown as above. The concentrations of haemolysin and monospecific antibodies were determined by the method of Markwell et al. (1978). The identity and purity of the suilysin preparation was verified by immunoblotting, with a monoclonal antibody directed against the suilysin (kindly provided by T. Jacobs, INTERVET, The Netherlands), and by silver staining, respectively. The titre of the purified suilysin was verified by lysis of horse red blood cells as described previously (Gottschalk et al., 1995).

Electron microscopy studies. LLC-PK1 cells were used for electron microscopy studies. For transmission electron microscopy (TEM), LLC-PK1 monolayers $\left(\sim 10^{5}\right.$ cells $)$ in $24-$ well tissue culture plates were infected with $10^{8}$ c.f.u. per well of exponential-phase $S$. suis suspension in culture medium. The plates were centrifuged at $800 \mathrm{~g}$ for $10 \mathrm{~min}$ to place bacteria at the surface of the cells and then incubated at $37^{\circ} \mathrm{C}$ with $5 \% \mathrm{CO}_{2}$, for $1 \mathrm{~h}, 2 \mathrm{~h}$ and $4 \mathrm{~h}$. The supernatants were removed by gentle aspiration; the cells were washed once with PBS, and the monolayers were fixed for $1 \mathrm{~h}$ at room temperature with $2 \%(\mathrm{v} / \mathrm{v})$ glutaraldehyde in $0 \cdot 1 \mathrm{M}$ cacodylate buffer $\mathrm{pH} 7 \cdot 2$ and then postfixed in $2 \%(\mathrm{v} / \mathrm{v})$ osmium tetraoxide in deionized water. Samples were dehydrated in a graded series of ethanol washes and embedded in ferm Spurr resin. Thin sections were cut with a diamond knife on an LKB Nova ultramicrotome (Leica) and poststained with uranyl acetate and lead citrate. Samples were examined with a model 420 electron microscope (Philips Electronics). For scanning electron microscopy (SEM), samples were treated as for the TEM, but after the ethanol washes, the preparations were then coated with gold-palladium after critical-point drying and observed using a Hitachi S-3000N microscope.

Statistics. All data are expressed as means \pm standard deviations (error bars). Data were analysed by two-tailed, unpaired $t$-test. A $P$ value of $<0.05$ was considered significant and a $P$ value of $<0 \cdot 01$ was considered highly significant.

\section{RESULTS}

\section{S. suis does not invade epithelial cells}

As shown in Fig. 1, S. suis did not have the capacity to invade the epithelial cells tested. Before using the standard conditions for comparative assays $\left(10^{5}\right.$ c.f.u. 


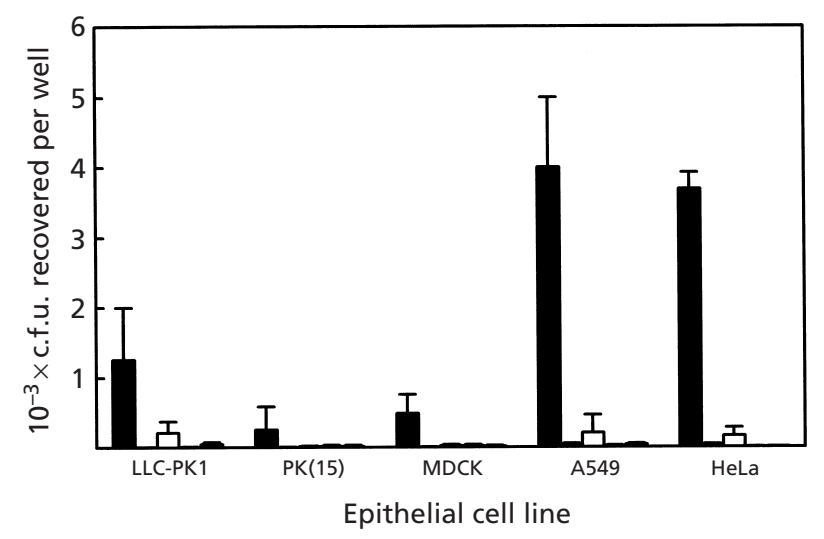

Fig. 1. Invasion of epithelial cell lines LLC-PK1, PK(15), MDCK,

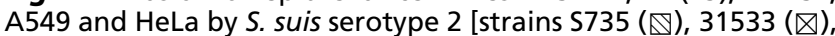
AAH4 $(\boxminus)$ and unencapsulated mutant 2A $(\square)$ ] and group B streptococci [strain $\mathrm{COH}_{1}(\boldsymbol{\square})$ ]. Results were determined after a $2 \mathrm{~h}$ exposure with $10^{5}$ c.f.u. per well, followed by an additional $2 \mathrm{~h}$ incubation in the presence of penicillin/gentamicin to kill extracellular bacteria, and epithelial cell lysis to retrieve $100 \mu \mathrm{l}$ aliquots of intracellular bacteria for viable plate counts.

per well, $2 \mathrm{~h}$ invasion time), many different variables were tested in order to find combinations that promote S. suis invasion. Different invasion times (e.g. $1 \mathrm{~h}, 2 \mathrm{~h}$ and $3 \mathrm{~h}$ ), inocula (e.g. $10^{2}$ to $10^{7}$ c.f.u. per well), exponential or stationary phase of bacterial growth, and serum concentrations (e.g. $5 \%$ and $10 \%$ ) were tested, but none induced $S$. suis invasion of epithelial cells (data not shown). In contrast, GBS strain COH1 was able to invade the human epithelial cell lines A549 and HeLa, with a significantly lower invasion of animal origin cell lines $(P<0 \cdot 01$, Fig. 1$)$. Since it has been reported that an unencapsulated strain of GBS invades epithelial cells at higher degree than the encapsulated parent strain (Hulse et al., 1993), the unencapsulated S. suis mutant 2A was also tested for its ability to invade epithelial cells. Unlike GBS, the unencapsulated strain 2A did not show enhanced invasion. Indeed, no significant differences were observed with respect to the parent strain $(P>$ $0 \cdot 05$, Fig. 1). It should be noted that the quantity of bacteria used for invasion or adherence assays was not toxic to the epithelial cell lines (see below). Finally, no intracellular bacteria were observed by TEM.

\section{S. suis adheres to epithelial cells}

In general, $S$. suis was able to adhere to epithelial cells (Fig. 2a). No significant differences were observed among the different strains $(P>0.05)$, and $S$. suis presented, in general, lower levels of adherence than those observed with GBS (Fig. 2a). Adherence levels were similar for exponential- and stationary-phase bacteria (data not shown). In order to examine the role of CPS in adherence, the adhesion levels of the unencapsulated mutant $2 \mathrm{~A}$ with the encapsulated parent strain S735 were compared. Increased adhesion levels were observed with the unencapsulated mutant as
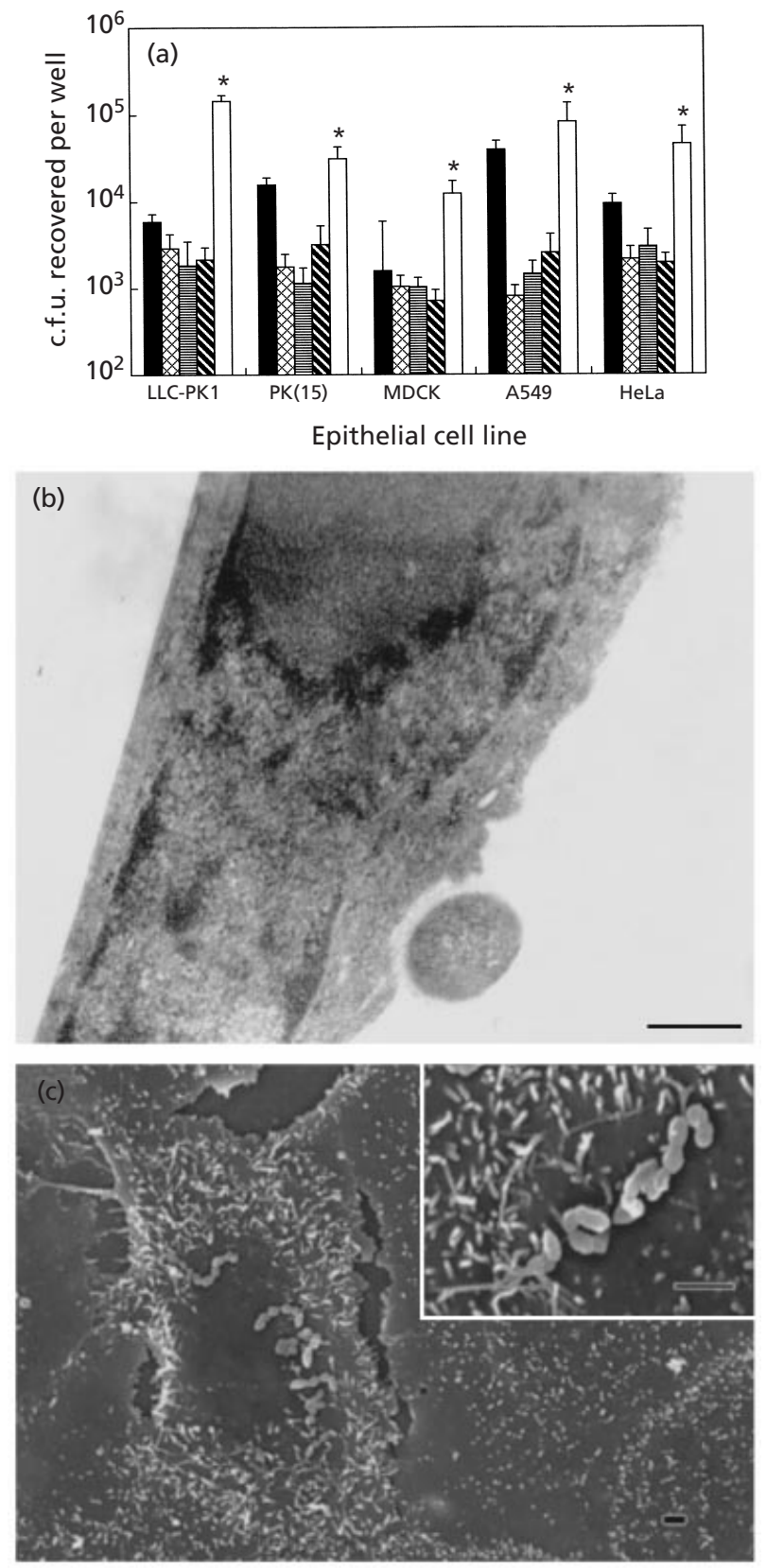

Fig. 2. (a) Adhesion of epithelial cell lines LLC-PK1, PK(15), MDCK, A549 and HeLa by S. suis serotype 2 [strains S735 ( $\$)$ ), $31533(\otimes)$, AAH4 $(\boxminus)$ and uncapsulated mutant $2 A(\square)]$ and group B streptococci [strain $\mathrm{COH} 1(\square)$ ]; *, $P<0.05$ versus adherence of the parent strain S735. Results were determined after a $2 \mathrm{~h}$ exposure with $10^{5}$ c.f.u. per well, followed by extensive washing of non-adherent bacteria and epithelial cell lysis to retrieve $100 \mu \mathrm{l}$ aliquots of total cell-associated bacteria for viable plate counts. (b) Transmission electron micrograph showing $S$. suis adhered to LLC-PK1; bar, $300 \mathrm{~nm}$. (c) Scanning electron micrograph (with enlarged inset) showing $S$. suis adhered to LLC-PK 1 ; bars, $2 \mu \mathrm{m}$.

compared to the parent strain, for all cell lines tested $(P$ $<0 \cdot 01$, Fig. 2a). Adhesion of $S$. suis to epithelial cells was confirmed by TEM and SEM (Fig. 2b, c). 

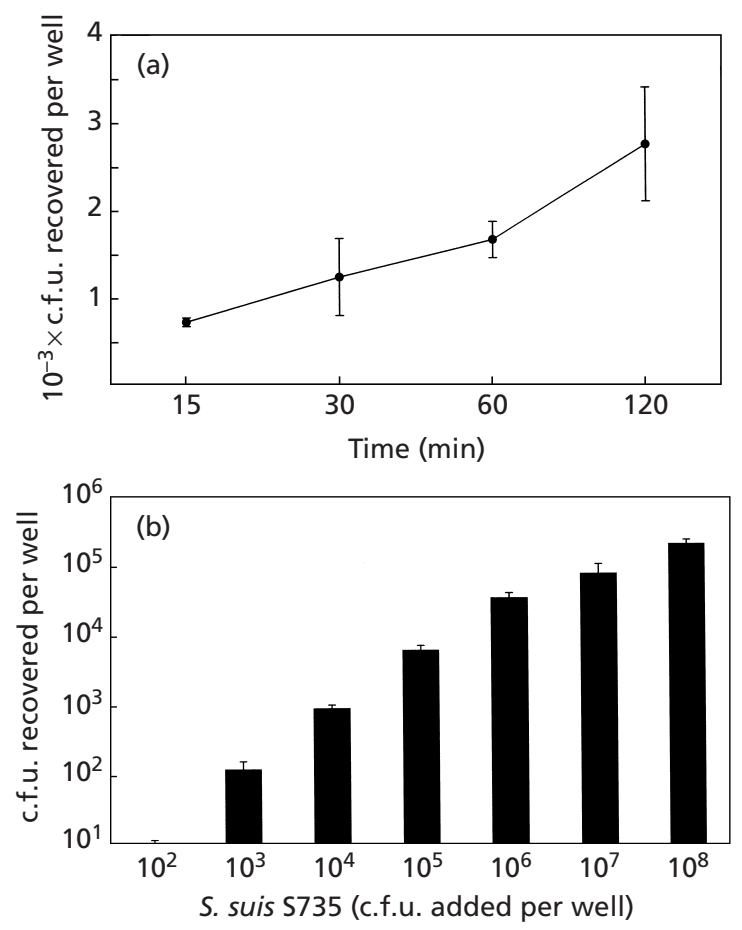

Fig. 3. Kinetics of adherence to epithelial cell line LLC-PK1 of $S$. suis serotype 2, strain $\mathrm{S} 735$ in (a) a time-dependent way in the presence of $10^{5}$ c.f.u. per well and (b) a dose-dependent way after $2 \mathrm{~h}$ incubation.

The cell line LLC-PK1 and the strain S735 were chosen for further study of $S$. suis adhesion to epithelial cells. Figs $3(a)$ and $3(b)$ show that $S$. suis adhered to epithelial cells in a time- and dose-dependent fashion. Using a concentration of $10^{5}$ c.f.u. per well, maximal adhesion was obtained at $120 \mathrm{~min}(P<0 \cdot 01$, Fig. 3a). Longer periods of incubation did not significantly increase the adhesion of $S$. suis to cells (data not shown). Maximum adhesion was observed at a concentration of $10^{8}$ c.f.u. per well (Fig. 3b). Adhesion did not increase for the nonhaemolytic strains using higher bacterial concentrations (data not shown). Higher bacterial concentrations of the haemolytic strains could not be used due to toxic effects (see below).

In order to obtain preliminary information about the interaction between $S$. suis and the epithelial cells, the inhibitory effect of protease treatment of bacteria was evaluated. In addition, a possible competition effect of a BSA-neoglycoconjugate (Gal $\alpha 1-4 \mathrm{Gal} \beta 1-4 \mathrm{Glc} \beta$-OCETE-BSA), a receptor already described for a $S$. suis adhesin (Haataja et al., 1993), as well as that of purified S. suis cell wall was studied. Trypsin or proteinase K treatment did not significantly affect $S$. suis adhesion to epithelial cells, nor did the addition of the BSAneoglycoconjugate (data not shown). On the other hand, $100 \mu \mathrm{g}$ purified cell wall $\mathrm{ml}^{-1}$ was able to inhibit $93 \%$ $( \pm 3 \%)$ of the adherence of $S$. suis to the epithelial cell line LLC-PK1.

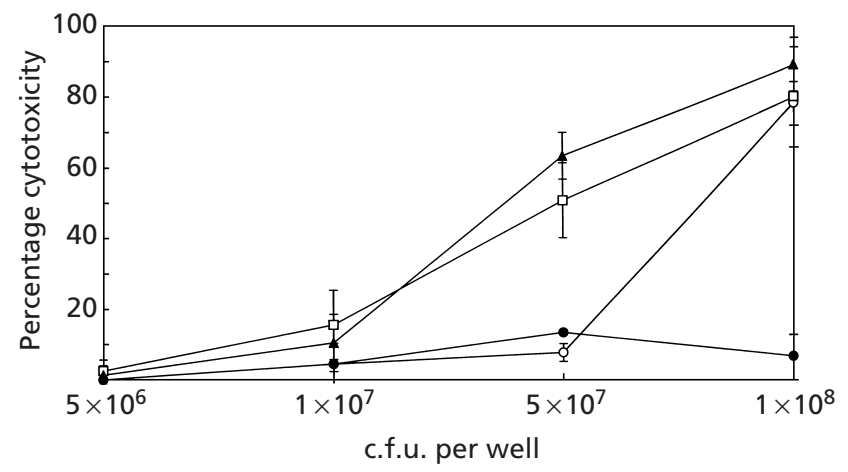

Fig. 4. Effect of $S$. suis concentration on LLC-PK1 injury. Haemolytic strains S735 ( $\square$ ) and 31533 ( $\mathbf{\Delta})$; non-haemolytic strain AAH4 (O) and GBS strain COH1 (O). LLC-PK1 cytotoxicity was determined by LDH release in the presence of different concentrations of $S$. suis strains after $4 \mathrm{~h}$ incubation.

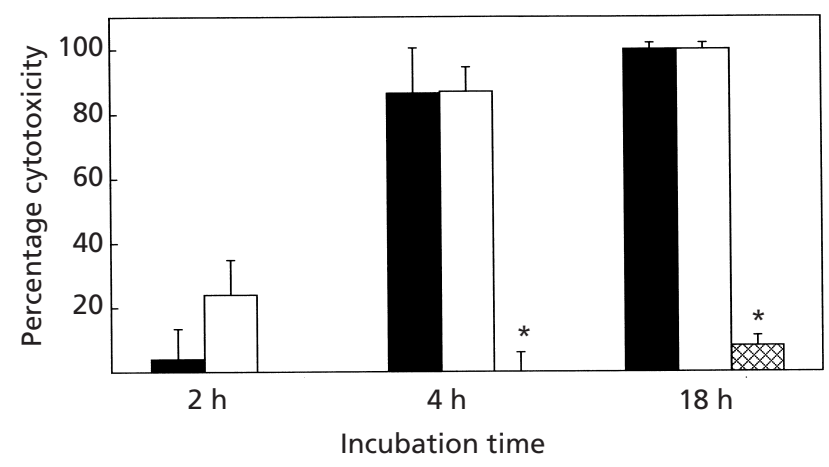

Fig. 5. Effect of incubation time in presence of $S$. suis haemolytic strains $31533(\square)$ and S735 ( $\square$ ) and non-haemolytic strain AAH4 (国) on LLC-PK1 injury; *, $P<0.01$ versus the haemolytic strains 5735 and 31533 ( $4 \mathrm{~h}$ and $18 \mathrm{~h}$ ). LLC-PK1 cytotoxicity was determined by LDH release in presence of $10^{8}$ c.f.u. per well after different incubation times.

\section{S. suis strains can damage epithelial cells}

LDH release measurements were performed to determine if $S$. suis could be cytotoxic to epithelial cells. The cell line LLC-PK1 was used as a model. Fig. 4 shows that $S$. suis strain AAH4 did not injure LLC-PK1, while strains S735 and 31533 were highly cytotoxic. Cytotoxicity was proportional to bacterial concentration, with maximum cytotoxic effect at $1 \times 10^{8}$ c.f.u. per well $(P<0 \cdot 01$, Fig. 4). S. suis cytotoxicity was higher than that observed for GBS: approximately $50 \%$ cytotoxicity was observed for strains S735 and 31533 whereas 10\% cytotoxicity was obtained for GBS at a bacterial concentration of $5 \times 10^{7}$ c.f.u. per well $(P<0 \cdot 01)$. Kinetic studies showed that cytotoxicity of strains increased over time and always remained higher than the nontoxic strain $(P<0 \cdot 01)$. Maximal cytotoxicity was observed at $4 \mathrm{~h}$ and did not significantly increase at $18 \mathrm{~h}$ (Fig. 5). Interestingly, the two highly cytotoxic strains 

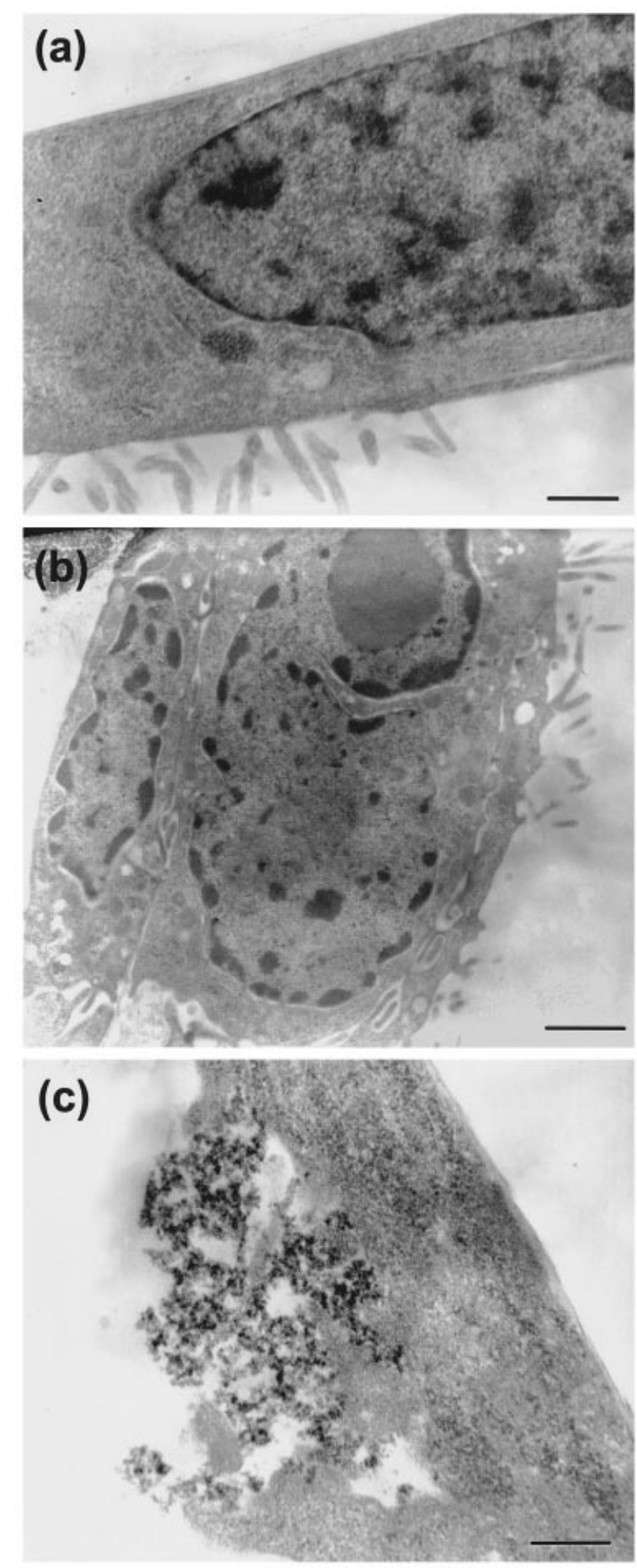

Fig. 6. Electron micrographs demonstrating LLC-PK1 injury with $10^{8}$ c.f.u. S. suis per well. (a) Non-infected control cells. (b, c) Cells incubated for $2 \mathrm{~h}$ with the non-suilysin-producing strain AAH4 (b) or the suilysin-producing strain $\$ 735$ (c). Bars, $1 \mu \mathrm{m} \mathrm{(a,}$ b); $300 \mathrm{~nm}$ (c). LLC-PK1 integrity after $2 \mathrm{~h}$ incubation with strain AAH4 was comparable to non-infected control cells. Injury was manifested by the lost of the cytoplasmic density, severe disruption of cellular membranes and loss of microvillus structures.

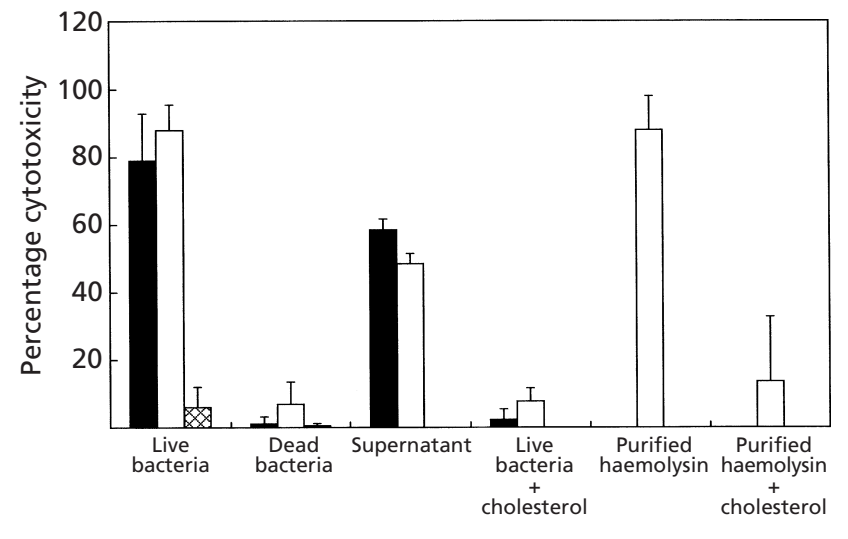

Fig. 7. Effects of different variables on the cytotoxic effect of $S$. suis serotype 2 strains $\mathrm{S735}(\square), 31533(\boldsymbol{\square})$ and AAH4 (国). Cholesterol $\left(400 \mu \mathrm{g} \mathrm{ml}^{-1}\right)$ was incubated with bacteria for $1 \mathrm{~h}$ prior to the addition to cells. LLC-PK1 cytotoxicity was determined by $\mathrm{LDH}$ release in the presence of different variables after $4 \mathrm{~h}$ incubation.

produce the suilysin (Gottschalk et al., 1995; Charland et al., 2000). TEM was used to confirm the toxicity of the suilysin-positive strain S735 to LLC-PK1 cells. Fig. 6(a) shows normal cell characteristics, which are kept after strain AAH4 infection $\left(10^{8}\right.$ c.f.u. per well $)$ of cells for $2 \mathrm{~h}$ (Fig. 6b). The nucleus was intact and dense regular cytoplasmic contents were observed. On the other hand, cells incubated with strain S735 presented cellular injury demonstrated by loss of cytoplasmic density, disappearance of the nucleus and discontinuity of cytoplasmic membranes (Fig. 6c).

\section{Suilysin-associated injury to LLC-PK1 cells}

It is known that suilysin is secreted to the growth supernatant in vitro (Gottschalk et al., 1995). Addition of the growth supernatant of the suilysin-producing strains S735 and 31533 to LLC-PK1 monolayers induced cell injury, whereas that of the suilysin-negative strain AAH4 did not affect the cells (Fig. 7). Different experiments were performed to determine the involvement of the suilysin in cell injury. First, to determine if cytotoxicity required live bacteria, strains 31533 and S735 were killed by heat treatment $\left(60^{\circ} \mathrm{C}, 45 \mathrm{~min}\right)$ and the suspension was added to a LLC-PK1 monolayer for $4 \mathrm{~h}$. The results showed that only live bacteria could induce LLC-PK1 injury (Fig. 7). This is in agreement with the fact that the suilysin was shown to be not cellbound (Gottschalk et al., 1995). Since washed bacteria were always used in the present study, only live bacteria were able to grow, to produce the suilysin and to be toxic to cells. Since it has been demonstrated that cholesterol is able to inhibit suilysin activity and toxicity (Gottschalk et al., 1995; Charland et al., 2000), live bacteria were mixed with cholesterol for $1 \mathrm{~h}$ and then added to LLC-PK1 monolayers. Fig. 7 shows that cholesterol significantly inhibited cytolytic activity of 
suilysin-producing strains $(P<0 \cdot 01)$. Furthermore, when purified suilysin $\left(10 \mu \mathrm{g} \mathrm{ml}^{-1}\right)$ was added to LLCPK1 monolayers, cytotoxicity was similar to that observed with live bacteria $(P>0 \cdot 05)$. Suilysin cytotoxicity was also inhibited by cholesterol treatment $(P$ $<0 \cdot 01$, Fig. 7).

\section{DISCUSSION}

S. suis is an important pathogen that causes significant economic losses to the swine industry. In addition, these bacteria represent a health risk for human beings working in close contact with swine or swine-derived products. It is thus important to understand the pathogenesis of $S$. suis infection in order to develop strategies for prevention or therapy.

As for other microbial pathogens, the process of S. suis infection is complex and multifactorial. Bacterial attachment to epithelial cells, colonization of mucosal surfaces as well as interactions with respiratory epithelial cells are prerequisites for the induction of some streptococcal infections. Interactions between epithelial cells and streptococci have already been described (Tamura et al., 1994; LaPenta et al., 1994). In addition, the lack of diffuse parenchymal lesions in most $S$. suis cases of meningitis may indicate an epithelial choroid plexus route of access to the CNS. In fact, lesions have been observed at the choroid plexus in natural or experimentally induced cases of $S$. suis meningitis (Williams \& Blakemore, 1990).

S. suis did not invade epithelial cells under the conditions tested in this study. The unencapsulated mutant $2 \mathrm{~A}$ did not show any difference of invasion when compared to the parent encapsulated strain. Many different variables were tested in order to find combinations that could favour invasion by $S$. suis; however, none of them were shown to induce invasion, even with epithelial cells of swine origin. These results disagree with a recent report published by Norton et al. (1999). In that study, it was shown that some $S$. suis strains were able not only to adhere, but also to invade (as a rare event) Hep-2 cells, as shown by differential fluorescence. These authors mentioned that attempts to measure invasion by killing extracellular bacteria gave inconsistent results. Differences in the techniques and cell lines used may explain these discrepancies. On the other hand, our study confirmed that GBS was able to invade epithelial cells of human origin, as previously described (Rubens et al., 1992). Results of this study suggest that interactions between S. suis and epithelial cells follow a pattern which is different for these two pathogens, as already shown with phagocytic cells (Segura et al., 1998) and endothelial cells (Charland et al., 2000).

This study has shown that $S$. suis is able to adhere to different epithelial cells in a time- and dose-dependent fashion. In addition, levels of adherence were, in general, similar in human- and animal-derived cells. GBS adhered to most cell lines in higher numbers than $S$. suis. As reported earlier (Tamura et al., 1994), a lower adherence of GBS to MDCK cells was observed. Unlike Streptococcus group A (LaPenta et al., 1994) and similarly to GBS (Tamura et al., 1994), adherence levels were similar for exponential- and stationary-phase bacteria.

Despite the fact that the CPS does not seem to prevent adherence, a significantly higher rate of adherence was observed in the absence of the CPS for all cell lines tested. Similarly, Salasia et al. (1995) showed an increased adherence rate of spontaneous unencapsulated mutants of S. suis serotype 2 to HeLa cell and rabbit lung macrophages. It has already been shown that an unencapsulated Streptococcus pneumoniae strain adhered to epithelial cells to a much greater extent than the encapsulated parental strain (Adamou et al., 1998). The influence of the CPS in epithelial adhesion of GBS is, on the other hand, more controversial (Wibawan et al., 1992; Tamura et al., 1994). St Geme \& Cutter (1996) suggested that encapsulation may be modulated depending on the infectious stage. Encapsulation may be down-regulated especially during colonization of epithelial cells (lungs, nasopharynx) and, once in the bloodstream, up-regulation of capsule production protects bacteria against the immune system, but it does not completely prevent adhesion to other cells (Charland et al., 2000). To date, however, there is no direct evidence of such encapsulation modulation for S. suis.

It has been reported that the $S$. suis CPS may prevent the interaction of the Gal $1-4$ Gal-binding P adhesin with erythrocytes and thus inhibit haemagglutination (Tikkanen et al., 1996). The haemagglutination activity is also inhibited by protease treatments (Kurl et al., 1989). After purification, Tikkanen et al. (1996) confirmed the protein nature of the adhesin. Because the erythrocyte receptor $\left(\mathrm{GbO}_{3}\right)$ is also found on epithelial tissues, it was decided in this study to verify if this receptor was implicated in the observed $S$. suis adhesion to epithelial cells. No significant adhesion inhibition was obtained when Gal $\alpha 1-4 \mathrm{Gal} \beta 1-4 \mathrm{Glc} \beta$-O-CETE-BSA was used. Furthermore, protease treatment of bacteria had no effect on adhesion to epithelial cells. Thus, the interactions between $S$. suis type 2 and epithelial cell lines observed in this study seem to be different, at least in part, to those described in the haemagglutination tests (Haataja et al., 1993; Tikkanen et al., 1996). In addition, a high inhibition effect of the adhesion to epithelial cells using $S$. suis purified cell wall was observed in this study. Cell wall components of group A streptococci, GBS and $S$. pneumoniae have already been described as being responsible for adhesion to host cells (Beachey, 1981; Nealon \& Mattingly, 1985; Andersson et al., 1988). The possible role of the lipoteichoic acid and/or the peptidoglycan in S. suis adhesion to epithelial cells remains to be confirmed.

It may be hypothesized that, after adherence of $S$. suis to epithelial cells, bacteria can secrete toxic factors which would lead to cell lysis, which could favour the disruption of the epithelial cell barrier and might facilitate access to the bloodstream and systemic spread by the organism (Nizet et al., 1996, 1997). In addition, 
the cell toxicity may increase BBB permeability, which could lead to the development of cerebral oedema, increased intracranial pressure and cerebral blood flow blockage characteristic of bacterial meningitis (Tauber, 1989). In the case of S. suis, the suilysin seems to be responsible for epithelial cell damage in vitro. Indeed, many lines of evidence implicate suilysin as the bacterial component responsible for cell cytotoxicity. Only suilysin-producing strains were toxic for the epithelial cells. In addition, the cytotoxic component was present in culture supernatants and toxicity increased by increasing time and bacterial concentrations, which correlates with the suilysin multi-hit activity mode of action (Gottschalk et al., 1995). Finally, cholesterol inhibited the toxic effect of suilysin-positive strains as well as that obtained with purified suilysin (Gottschalk et al., 1995; Jacobs et al., 1994). The suilysin has already been shown to be toxic for endothelial cells (Charland et al., 2000), phagocytic cells (Segura \& Gottschalk, 1999) and the Hep-2 epithelial cell line (Norton et al., 1999). It is known that GBS $\beta$-haemolysin causes injury of lung epithelial cells and brain endothelial cells in vitro (Nizet et al., 1996, 1997). It should be noted that at a similar bacterial concentration, $S$. suis is much more toxic to LLC-PK1 than GBS. Pneumolysin, a member of the same family of toxins as suilysin, is also known to damage epithelial cells (Rubins et al., 1992). In this study, virulent non-haemolytic strains did not induce cytotoxicity. Since North American and European isolates are phenotypically and genetically distinct (Gottschalk et al., 1998; Chatellier et al., 1999), different virulence factors are probably involved in the pathogenesis of the infection caused by the two groups of strains.

The results described herein give additional evidence that pathogenesis of the infection differs between $S$. suis and GBS (Segura et al., 1998; Charland et al., 2000). In particular, it is possible that suilysin-positive $S$. suis strains use adherence and cell injury, as opposed to direct cellular invasion, as part of a complicated multistep process which leads to bacteraemia and meningitis in pigs.

\section{ACKNOWLEDGEMENTS}

We would like to thank D. Montpetit from the Centre de Recherche et Développement sur les Aliments (CRDA) for the transmission and scanning electron micrographs. We also thank R. Higgins for critical review of the manuscript. This work was supported by Grant 0GP0154280 from the Natural Sciences and Engineering Research Council of Canada to M.G.

\section{REFERENCES}

Adamou, J. E., Wizemann, T. M., Barren, P. \& Langermann, S. (1998). Adherence of Streptococcus pneumoniae to human bronchial epithelial cells (BEAS-2B). Infect Immun 66, 820-822.

Andersson, B., Beachey, E. H., Tomasz, A., Tuomanen, E. \& Svanborg-Edén, C. (1988). A sandwich adhesin on Streptococcus pneumoniae attaching to human oropharyngeal epithelial cells in vitro. Microb Pathog 4, 267-278.
Arends, J. P. \& Zanen, H. C. (1988). Meningitis caused by Streptococcus suis in humans. J Infect Dis 10, 131-137.

Beachey, E. H. (1981). Bacterial adherence: adhesin-receptor interactions mediating the attachment of bacteria to mucosal surfaces. J Infect Dis 143, 325-345.

Betz, A. L. \& Goldstein, G. W. (1986). Specialized properties and solute transport in brain capillaries. Annu Rev Physiol 48, 241-250.

Charland, N., Harel, J., Kobisch, M., Lacasse, S. \& Gottschalk, M. (1998). Streptococcus suis serotype 2 mutants deficient in capsular expression. Microbiology 144, 325-332.

Charland, N., Nizet, V., Rubens, C., Kim, K., Lacouture, S. \& Gottschalk, M. (2000). Streptococcus suis serotype 2 interactions with human brain microvascular endothelial cells. Infect Immun 68, 637-643.

Chatellier, S., Gottschalk, M., Higgins, R., Brousseau, R. \& Harel, J. (1999). Relatedness of Streptococcus suis serotype 2 isolates form different geographic origins as evaluated by molecular fingerprinting and phenotyping. J Clin Microbiol 37, 362-366.

Gottschalk, M., Lacouture, S. \& Dubreuil, J. D. (1995). Characterization of Streptococcus suis capsular type 2 haemolysin. Microbiology 141, 189-195.

Gottschalk, M., Lebrun, A., Wisselink, H., Dubreuil, J. D., Smith, H. \& Vecht, U. (1998). Production of virulence-related proteins by Canadian strains of Streptococcus suis capsular type 2. Can J Vet Res 62, 75-79.

Haataja, S., Tikkanen, K., Liukkonen, J., François-Gérard, C. \& Finne, J. (1993). Characterization of a novel bacterial adhesion specificity of Streptococcus suis recognizing blood group P receptor. J Biol Chem 268, 4311-4317.

Higgins, R. \& Gottschalk, M. (1999). Streptococcal diseases. In Diseases of Swine, 8th edn, pp. 563-570. Edited by A. D. Leman, B. E. Straw, W. L. Mengeling, S. D’Allaire \& D. J. Taylor. Ames, IA: Iowa State University Press.

Hulse, M. L., Smith, S., Chi, E. Y., Pham, A. \& Rubens, C. E. (1993). Effect of type III group B streptococcal capsular polysaccharide on invasion of respiratory epithelial cells. Infect Immun 61, 4835-4841.

Jacobs, A. A. C., Loeffen, P. L. W., Van Den Berg, A. J. G. \& Strom, P. K. (1994). Identification, purification and characterization of a thiol-activated hemolysin (suilysin) of Streptococcus suis. Infect Immun 62, 1742-1748.

Kurl, D. N., Haataja, S. \& Finne, J. (1989). Hemagglutination activities of group B, C, D and G streptococci: demonstration of novel sugar-specific cell-binding activities in Streptococcus suis. Infect Immun 57, 384-389.

LaPenta, D., Rubens, C., Chi, E. \& Cleary, P. P. (1994). Group A streptococci efficiently invade human respiratory epithelial cells. Proc Natl Acad Sci USA91, 12115-12119.

Markwell, M. A. K., Haas, S. M., Bieber, L. L. \& Tolbert, N. E. (1978). A modification of the Lowry procedure to simplify protein determination in membrane and lipoprotein samples. Anal Biochem 87, 206-210.

Nealon, T. J. \& Mattingly, S. J. (1985). Kinetic and chemical analyses of the biologic significance of lipoteichoic acids in mediating adherence of serotype III group B streptococci. Infect Immun 50, 107-115.

Nizet, V., Gibson, R. L., Chi, E. Y., Framson, P. E., Hulse, M. \& Rubens, C. E. (1996). Group B streptococcal beta-hemolysin expression is associated with injury of lung epithelial cells. Infect Immun 64, 3818-3826.

Nizet, V., Kim, K. S., Stins, M., Jonas, M., Chi, E. Y., Nguyen, D. \& 
Rubens, C. E. (1997). Invasion of brain microvascular endothelial cells by group B streptococci. Infect Immun 65, 5074-5081.

Norton, P. M., Rolph, C., Ward, P. N., Bentley, R. W. \& Leigh, J. A. (1999). Epithelial invasion and cell lysis by virulent strains of Streptococcus suis is enhanced by the presence of suilysin. FEMS Immunol Med Microbiol 26, 25-35.

Rubens, C. E., Smith, S., Hulse, M., Chi, E. Y. \& van Velle, G. (1992). Respiratory epithelial cell invasion by group B Streptococci. Infect Immun 60, 5157-5163.

Rubins, J. B., Duane, P. G., Charboneau, D. \& Janoff, E. N. (1992). Toxicity of pneumolysin to pulmonary endothelial cells in vitro. Infect Immun 60, 1740-1746.

Salasia, S. I. O., Lämmler, C. \& Herrmann, G. (1995). Properties of a Streptococcus suis isolate of serotype 2 and two capsular mutants. Vet Microbiol 45, 151-156.

Segers, R. P. A. M., Kenter, T., de Haan, L. \& Jacobs, A. C. (1998). Characterization of the gene encoding suilysin from Streptococcus suis and expression in field isolates. FEMS Microbiol Lett 167, 255-261.

Segura, M. \& Gottschalk, M. (1999). Adhesion of Streptococcus suis capsular type 2 to phagocytic cells. In Abstracts of the XIV Lancefield International Symposium on Streptococci and Streptococcal Diseases, Auckland, New Zealand, abstract P8.17.

Segura, M. A., Cléroux, P. \& Gottschalk, M. (1998). Streptococcus suis and group B Streptococcus differ in their interactions with murine macrophages. FEMS Immunol Med Microbiol 21, 189-195.

Segura, M., Stankova, J. \& Gottschalk, M. (1999). Heat-killed Streptococcus suis capsular type 2 strains stimulate tumor necrosis factor alpha and interleukin 6 production by murine macrophages. Infect Immun 67, 4646-4654.

Smith, H. E., Damman, M., van der Velde, J., Wagenaar, F., Wisselink, H. J., Stockhofe-Zurwieden, N. \& Smits, M. A. (1999). Identification and characterization of the cps locus of Streptococcus suis serotype 2: the capsule protects against phagocytosis and is an important virulence factor. Infect Immun 67, 1750-1756.
St Geme, J. W., III \& Cutter, D. (1996). Influence of pili, fibrils, and capsule on in vitro adherence by Haemophilus influenzae type b. Mol Microbiol 21, 21-31.

Tamura, G. S., Kuypers, J. M., Smith, S., Raff, H. \& Rubens, C. E. (1994). Adherence of group B streptococci to cultured epithelial cells: roles of environmental factors and bacterial surface components. Infect Immun 62, 2450-2458.

Tauber, M. G. (1989). Brain edema, intracranial pressure and cerebral blood flow in bacterial meningitis. Pediatr Infect Dis 8, 915-917.

Tikkanen, K., Haataja, S. \& Finne, J. (1996). The galactosyl-( $\alpha 1-4)$ galactose-binding adhesin of Streptococcus suis: occurrence in strains of different hemagglutination activities and induction of opsonic antibodies. Infect Immun 64, 3659-3665.

Trottier, S., Higgins, R., Brochu, G. \& Gottschalk, M. (1991). A case of human endocarditis due to Streptococcus suis in North America. Rev Infect Dis 13, 1251-1252.

Tuomanen, E. (1996). Entry of pathogens into the central nervous system. FEMS Microbiol Rev 18, 289-299.

Tunkel, A. R. \& Scheld, W. M. (1993). Pathogenesis and pathophysiology of bacterial meningitis. Clin Microbiol Rev 6, 118-136.

Vecht, U., Wisselink, H. J., Jellema, M. L. \& Smith, H. E. (1991). Identification of two proteins associated with virulence of Streptococcus suis type 2. Infect Immun 59, 3156-3162.

Wibawan, I., Lammler, C. \& Pasaribu, F. H. (1992). Role of hydrophobic surface proteins in mediating adherence of group B streptococci to epithelial cells. J Gen Microbiol 138, 1237-1242.

Williams, A. E. \& Blakemore, W. F. (1990). Pathogenesis of meningitis caused by Streptococcus suis type 2. J Infect Dis 162, 474-481.

Received 15 February 2000; revised 18 April 2000; accepted 26 April 2000. 